permits samples to be boiled under closely controlled conditions at low moisture content. The drying of certain types of confectionery deposited in starch moulds is being studied in two ways with the view of reducing the 'stoving time' necessary for their production. First, the effects of temperature and humidity on the rate of drying of gelatine and starch gums are being studied in a cabinet in which these factors can be closely controlled. Secondly, as corn-starch is used as a moulding medium, an investigation of its equilibrium relative humidity at elevated temperatures is of importance, and an apparatus for carrying this out has been devised and built by the staff of the Association. Other items of research connected with sugar confectionery manufacture are concerned with the properties of glucose used in confectionery (corn syrup), particularly the prevention of foaming on boiling and the tendency for the material to darken on storage.

The programme of research for the meat products group includes biochemical studies on residual tissue respiration and the measurement of oxidationreduction potential. Colour changes and fading in cooked cured-meats are being studied with the aid of reflectance spectrophotometry. On the technological level, cooking properties of sausages and their colour stability during marketing are being investigated.

The Association's bacteriological laboratory is concerned on one hand with problems connected with bacterial spoilage of food, including the 'blowing' of canned goods, greening in cooked cured-meats and bacterial growth in vacuum-packaged bacon, and on the other hand, with bacterial aspects of the curing and processing of meat. Members are also advised on questions relating to general factory hygiene.

Problems connected with the canning of herrings are being studied by members of the Association's staff at the Torry Research Station, Aberdeen. The work involves chemical studies of herring flesh and the correlation of changes in the constituents of the flesh with flavour changes and with changes in texture which occur during the canning process.

The Association maintains close contact with horticultural stations concerned with the breeding and development of new varieties of soft fruits and helps the industry to assess their suitability for jam manufacture. The tendency for raspberry seeds to go 'blind', that is to say, become less visible, in jam is another problem which has engaged the close attention of the Association.

Much of the work in connexion with pickles and sauces is concerned with microbiological spoilage, and spoilage organisms from a large number of spoiled packs have been isolated and identified. Problems connected with the production of low-acid pickles involve studies of the pasteurization procedures necessary for a product which will combine adequate shelf-life with desirable appearance and eating properties.

In conjunction with the National Institute for Research in Dairying, an instrument for comparing the 'spreadability' of margarines has been developed. This instrument, the 'Fira/Nird' extruder, has proved to have applications in connexion with other foods and, indeed, in other industries, where the rheological properties of semi-solid materials are important.

The Association maintains an extensive library of books and periodicals. Research reports and other publications are available only to members of the Association, who also receive monthly issues of abstracts from current scientific and technical literature. Some two thousand items are abstracted in a year.
B. R. KNAPP

\title{
THE STRUCTURE AND CHEMISTRY OF PROTEINS
}

\section{SYMPOSIUM ON PROTEINS AT PARKVILLE, AUSTRALIA}

$\mathrm{T}$ HE intensification in recent years of research relating to the utilization of the primary products of Australia, wool, meat, wheat and milk, and in medical research, resulted in the organization during September 10-11 of a symposium on "The Structure and Chemistry of Proteins", at the Division of Protein Chemistry of the Commonwealth Scientific and Industrial Research Organization Wool Research Laboratories, Parkville, Victoria.

The meeting was well attended, with eighty-five delegates participating. Several overseas visitors were present, including some who had attended a symposium on "Hæmatin Enzymes" in Canberra, immediately preceding the symposium on proteins.

The topics of the twenty-two papers presented ranged over many of the fields currently being investigated in other parts of the world, a notable exception, however, being studies of amino-acid sequences. This reflects the pre-occupation of Australian workers with the isolation and characterization of protein components from natural products as a necessary first step to a more comprehensive understanding of their structure. Although the complex protein mixtures of these products are the focal point of much of the Australian research, studies involving purified soluble proteins, such as insulin and lysozyme, plasma albumin and other proteins as well as synthetic peptides are, however, also in progress. The rapid advances which are being made in our knowledge of the amino-acid sequence, struc. ture and behaviour of these classical proteins assist in the understanding and interpretation of the chemistry of the more complex biological systems.

The contributions that X-ray, infra-red and electron-microscope investigations have made in the study of the structural organization of keratin were illustrated by the work of R. D. B. Fraser, T. P. MacRae and G. E. Rogers. The application of X-ray crystallography to the study of the three-dimensional structure of a simpler compound, toluene- $p$-sulphonylL-prolyl-L-hydroxyproline monohydrate, was described by J. Fridrichsons and A. McL. Mathieson, and this contribution emphasized the stereo-chemical problem encountered with prolyl residues in a poly. peptide chain. The properties of protein complexes of the insect cuticle were described by R. H. Hackman and interest was aroused in the nature of their strong bonding to chitin and quinones. The isolation 
of nucleoproteins and labile plant viruses from leaves and their susceptibility to degradation by salt were discussed by $J$. W. Lyttieton.

The chemistry of thiols and disulphides is a prominent feature of protein chemistry and was exhaustively discussed. S. J. Leach and J. M. Swan described the important analytical advances made in this field with the aid of the polarograph and the preparative applications of sulphite in the presence of an oxidizing agent, such as cupric ions. The various methods of splitting disulphide bonds and their application in the extraction of soluble proteins from wool were discussed by J. M. Gillespie, I. J. O'Donnell and E. O. P. Thompson, and H. Lindley reported on the varying reactivity of the disulphide bonds of insulin. J. M. Creeth and D. J. Winzor were concerned with the specificity of the reaction of iodine with the sulphydryl groups of ovalbumin, while the important role of thiols in disulphide interchange reactions was clearly apparent in the experiments of F. J. R. Hird, R. Frater and J. R. Yates on the nature of cohesive forces in dough. Disulphide interchange was also responsible for the inhibition of several - $\mathrm{SH}$ enzymes by "sulphanilamide disulphides' in an investigation reported by $\mathrm{E}$. Boeri and $\mathrm{L}$. Brighenti.

The physico-chemical characterization of proteins isolated from naturally occurring mixtures was covered in a further series of papers. The aggregation and disaggregation of soluble proteins and the changes induced during denaturation figured prominently in the discussions of papers presented by J. M. Creeth and L. W. Nicol on urease, by B. S. Harrap, I. J. O'Donnell and E. F. Woods on soluble wool proteins and by H. A. McKenzie on various enzymes and globular proteins. The various techniques used to follow conformation changes were critically examined and it became clear that the behaviour of a particular protein in any given system was not necessarily indicative of the behaviour of other proteins in the same system. The surface denaturation of proteins was discussed by F. MacRitchie and the application of the spread monolayer techniques to a comparison of the surface chemical properties of various cereal proteins was described by N. W. Tschoegl. The preparative applications of electrophoresis were

\section{ELECTRONICS EXHIBITION}

$\mathrm{T}$ HE fourteenth Exhibition of Electronic Devices, organized by the Northern Division of the Institution of Electronics, was held at the Manchester College of Science and Technology during July 9-15. This annual exhibition is now well established and it provides an opportunity for new electronic apparatus to be demonstrated in rather less crowded conditions than obtain at the Physical Society Exhibition held in London during January.

A lecture programme was associated with the exhibition and, as is to be expected, a substantial part of this programme was devoted to transistor techniques. However, topics of general scientific interest were by no means excluded, and lectures on the argon chromatograph, on photographic densitometry and on the use of X-rays for micro-analysis were well attended.

The exhibition was divided into a manufacturers' section and a research section, the research exhibits sixty manufacturers. illustrated by the work of J. F. O'Dea on the isolation of components of serum while P. R. Carnegie and R. L. M. Synge described the electrophoretic behaviour of cupric complexes of oligopeptides and a possible method for selectively isolating dipeptides from mixtures of peptides.

Chromatography as an aid in the purification of proteins was introduced by A. G. M. Marr, who described the fractionation of serum proteins on 'DEAE-cellulose'. D. H. Simmonds has applied this technique very successfully to the water-soluble flour proteins and he also reported amino-acid analyses of the various fractions using ion-exchange chromatography with an automatic recording apparatus capable of handling eight ion-exchange columns eluted simultaneously. The continued interest of chemists in the quantitative analysis of protein constituents was evident in this paper and that of J. H. Bradbury on an alternative method requiring paper chromatography of dinitrophenyl amino-acids. This method was particularly applicable to the estimation of amide groups.

G. Coleman and W. H. Elliot described their work on the synthesis of $\alpha$-amylase by Bacillus subtilis and C. J. Shepherd discussed the effect of inhibitors of protein synthesis in Aspergillus nidulans.

A feature of the symposium was a lecture by Dr. R. L. M. Synge on "Naturally Occurring Peptides and Their Biological Significance". Although the search for naturally occurring peptides has not been intensive it was apparent from the stimulating survey by Dr. Synge that many unusual types of small peptide are already known. He went on to stress the necessity for quantitative data in the study of protein synthesis and expressed concern at the lack of experimental documentation for many of the generalizations by biochemists regarding the synthesis of proteins. A spirited discussion ensued and was continued in a subsequent session on protein synthesis.

Participants in the symposium were fortunate in having a range of papers presented covering most of the rapidly growing areas of investigation in the protein field and it may be hoped that similar conferences will be held in the future.

E. O. P. Thompson

forming much the smaller part of the whole. A relatively small number of research exhibits, especially from universities, has also been evident at the Physical Society Exhibition. Although research exhibits are of considerable general interest, and of special interest to those working in related fields, it is probable that for scientific workers as a whole the more important function of an exhibition of this type is to show instruments that are currently available. In the manufacturers' section this year's exhibition was notable for the extent of the exhibits of the various electronic agencies. These agencies handle the products of a number of manufacturers and they hold stocks of instruments and components. In the case of one agency the display occupied a whole room and included examples of the products of some

Included in the new equipment on show were examples of 'second generation' oscilloscopes. Until 